\title{
Síndrome de Miller-Fisher asociado a postinfección por SARS-CoV-2 en un paciente pediátrico
}

\author{
Miller-Fisher syndrome associated with post-infection \\ by SARS-CoV-2 in a pediatric patient
}

\author{
Carlos Javier Puppo Castro,* Héctor Rodrigo Cardoso Enciso,* \\ Sabino Suárez Hortiales, ${ }^{\ddagger}$ Perla Xóchitl Velázquez Durán ${ }^{\S}$ \\ * Pediatría Médica. \\ ₹ Neurología Pediátrica. \\ \& Infectología Pediátrica. \\ Centro Médico Naval. Ciudad de México.
}

\section{RESUMEN}

Se trata de un femenino de 11 años de edad con cefalea, dolor abdominal generalizado y fiebre de $38.5^{\circ} \mathrm{C}$; se realiza prueba de detección mediante PCR (+) SARS-CoV-2. Posteriormente acude a urgencias con cefalea, dolor abdominal, parestesias en manos que progresan a miembros superiores e inferiores, debilidad muscular, disfagia y dolor retroesternal. A la exploración física, los reflejos de estiramiento muscular (REM) en miembros superiores proximal y distal ++/++++, REM en miembros inferiores +/++++ proximal y $0 /++++$ distal. Fuerza muscular (Daniels) en miembros inferiores proximal y distal 4; fuerza muscular de miembros superiores 4 proximal y 3 distal. El estudio electroneuromiográfico se reporta con neuropatía motora axonal severa de las cuatro extremidades. En la resonancia magnética de cráneo y columna se observó reforzamiento anormal de las raíces de la cauda equina y cono medular, compatibles con polirradiculopatía desmielinizante aguda. El síndrome de Miller-Fisher (SMF) secundario a la infección por SARS-CoV-2 se reporta en siete casos en adultos y escasos reportes en niños alrededor del mundo. Las complicaciones neurológicas graves en este grupo etario son menores al $1 \%$ de los casos y principalmente observados en COVID-19 grave.

Palabras clave: SARS-CoV-2, síndrome de Miller-Fisher, polirradiculopatía desmielinizante.

\section{ABSTRACT}

A 11-year-old female with headache, generalized abdominal pain and fever of $38.5^{\circ} \mathrm{C}$; SARS-CoV-2 RT-PCR (+) detection test was performed. After a few days, he went to the emergency room with headache, abdominal pain, paresthesias in the hands that progressed to the upper and lower limbs, muscle weakness, dysphagia and retrosternal pain. On physical examination, muscle stretch reflexes (MSR) in proximal and distal upper limbs ,++++++ MSR in lower limbs +/++++ proximal and $0 /++++$ distal. Muscle strength (Daniels scale) in proximal and distal lower limbs 4; muscle strength of upper limbs 4 proximal and 3 distal. The electroneuromyographic study is reported with severe axonal motor neuropathy in four extremities. The MRI of the skull and spine applied abnormal enhancement of the roots of the equine tail and medullary cone, compatible with acute demelizing polyradiculopathy. Miller-Fisher syndrome (MFS) secondary to SARS-CoV-2 infection is reported in seven cases in adults and few reports in children around the world. Serious neurological complications in this age group are less than $1 \%$ of cases and mainly observed in severe COVID-19.

Keywords: SARS-CoV-2, Miller-Fisher syndrome, demelizing polyradiculopathy.

Citar como: Puppo CCJ, Cardoso EHR, Suárez HS, Velázquez DPX. Síndrome de Miller-Fisher asociado a postinfección por SARSCoV-2 en un paciente pediátrico. Rev Latin Infect Pediatr. 2021; 34 (4): 183-186. https://dx.doi.org/10.35366/102968

Recibido: 26-07-2021. Aceptado: 16-08-2021.

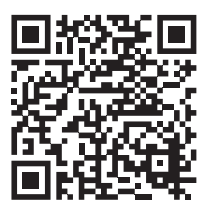




\section{INTRODUCCIÓN}

EI COVID-19 causado por SARS-CoV-2 es responsable de la presente pandemia. En niños se ha reportado una baja incidencia de casos graves $(5.9 \%)$ en comparación con los adultos $(18.5 \%) .{ }^{1}$ En un estudio publicado por Parcha et al, se describe una cohorte de 12,306 pacientes con COVID-19, donde la población pediátrica representó sólo el 13\% de todos los casos en Estados Unidos. Los síntomas más frecuentes fueron poco específicos; mialgias, artralgias, hiposmia o disgeusia (18.8\%), tos y disnea (16.5\%), dolor abdominal, diarrea, vómito y náusea $(13.9 \%)$ y síntomas neurológicos como cefalea (4.8\%). Únicamente el $5.5 \%$ de los pacientes fueron hospitalizados, el $13.7 \%$ de este grupo presentaron alguna alteración neurológica, las crisis convulsivas fueron las más frecuentes. ${ }^{2}$

Las manifestaciones clínicas neurológicas en los pacientes pediátricos son poco frecuentes. En un metaanálisis realizado por Panda et al, describen la frecuencia de síntomas inespecíficos como cefalea, mialgias y fatiga en el $16.7 \%$ de la población estudiada; mientras que las crisis convulsivas y signos meníngeos fueron mucho menos frecuentes (1\%). Las manifestaciones graves como encefalopatía, se han atribuido a diversos factores, como el efecto neurotrópico del virus y el daño secundario a hipoxia o choque séptico.

Los reportes de enfermedades como el síndrome de Guillain-Barré, hemorragia intracraneal, parálisis de nervios craneales o alteraciones visuales, son raros. ${ }^{3}$ En estos pacientes los estudios de gabinete son inespecíficos; sin embargo, se han observado cambios en la señal del músculo esplenio en la resonancia magnética, actividad lenta en el electroencefalograma y cambios miopáticos o neuropáticos leves en los estudios de conducción electromiográfica. ${ }^{4}$

El síndrome de Miller-Fisher es una variante del síndrome de Guillain-Barré, el cual se caracteriza por la triada clásica oftalmoplejía, arreflexia y ataxia. Afecta principalmente al sexo masculino en proporción 2:1; la presentación en niños es rara, limitándose a reportes de caso. ${ }^{5}$ Las manifestaciones clínicas autonómicas como hipertensión, taquicardia, sudoración nocturna, anticuerpos anti-GQ1b positivos y oftalmoplejía bilateral, son menos frecuentes en niños que en adultos. ${ }^{6}$ Las enfermedades infecciosas juegan un papel importante en la etiopatogenia de este síndrome; se ha asociado a infección por citomegalovirus, virus del Zika, virus de la inmunodeficiencia humana, virus de Epstein-Barr y Campylobacter jejuni. Actualmente, sólo siete adultos han sido reportados con este síndrome asociado a COVID-19.7,8

\section{PRESENTACIÓN DEL CASO}

Paciente femenino de 11 años de edad que acude por primera vez al Servicio de Urgencias con cefalea, dolor abdominal generalizado y fiebre de $38.5{ }^{\circ} \mathrm{C}$; se realiza prueba de detección mediante PCR de SARS-CoV-2, con resultado positivo y es tratada con analgésicos. Siete días después, presenta exantema maculopapular de distribución cefalocaudal que remite sin tratamiento. Cinco días después, acude nuevamente al Servicio de Urgencias por cefalea, dolor abdominal, parestesias en manos que progresan a miembros superiores e inferiores, debilidad muscular, disfagia y dolor retroesternal.

A la exploración física, la paciente presentó funciones mentales normales para la edad, Glasgow 15, nervios craneales íntegros; movimientos oculares conjugados y simétricos, motor con tono conservado. Reflejo de estiramiento muscular (REM) en miembros superiores proximal y distal ++/++++, REM en miembros inferiores +/++++ proximal y $0 /++++$ distal. Fuerza muscular en miembros inferiores proximal y distal 4/5; fuerza muscular de miembros superiores $4 / 5$ proximal y $3 / 5$ distal en la escala de Daniels.

Se realizó punción lumbar, el análisis celular y bioquímico del líquido cefalorraquídeo fue de características normales, no se detectaron microorganismos por PCR multiplex ni cultivos. Los anticuerpos antiestreptolisina $\mathrm{O}$, anticuerpos antipéptido cíclico citrulinado, el factor reumatoide y los anticuerpos antinucleares por inmunofluorescencia indirecta fueron negativos. Los títulos de anticuerpos polimiositis/esclerodermia fueron $75++$, de patrón granular 1:100, los anticuerpos moteado denso fino con peso molecular de $70 \mathrm{kDa}+$, el antígeno A relacionado con el síndrome de Sjögren + y anti-Ro 52+. El estudio electroneuromiográfico reportó neuropatía motora axonal severa de las cuatro extremidades. El estudio de conducción nerviosa fue normal. En la tomografía de cráneo no se observaron alteraciones (Figura 1). En la resonancia magnética de cráneo y columna se observó reforzamiento anormal de las raíces de la cauda equina y cono medular, compatibles con polirradiculopatía desmielinizante aguda (Figura 2). 
Figura 1:

A y B) Tomografía computarizada de cráneo con tejidos blandos y ósea del cráneo sin alteraciones.

Espacio subaracnoideo conserva su amplitud, adecuada diferenciación de sustancia gris blanca con densidad homogénea. Sistema ventricular supra e infratentorial conservada. Estructuras de la línea media, tallo cerebral y cerebelo sin alteraciones en su forma o densidad.
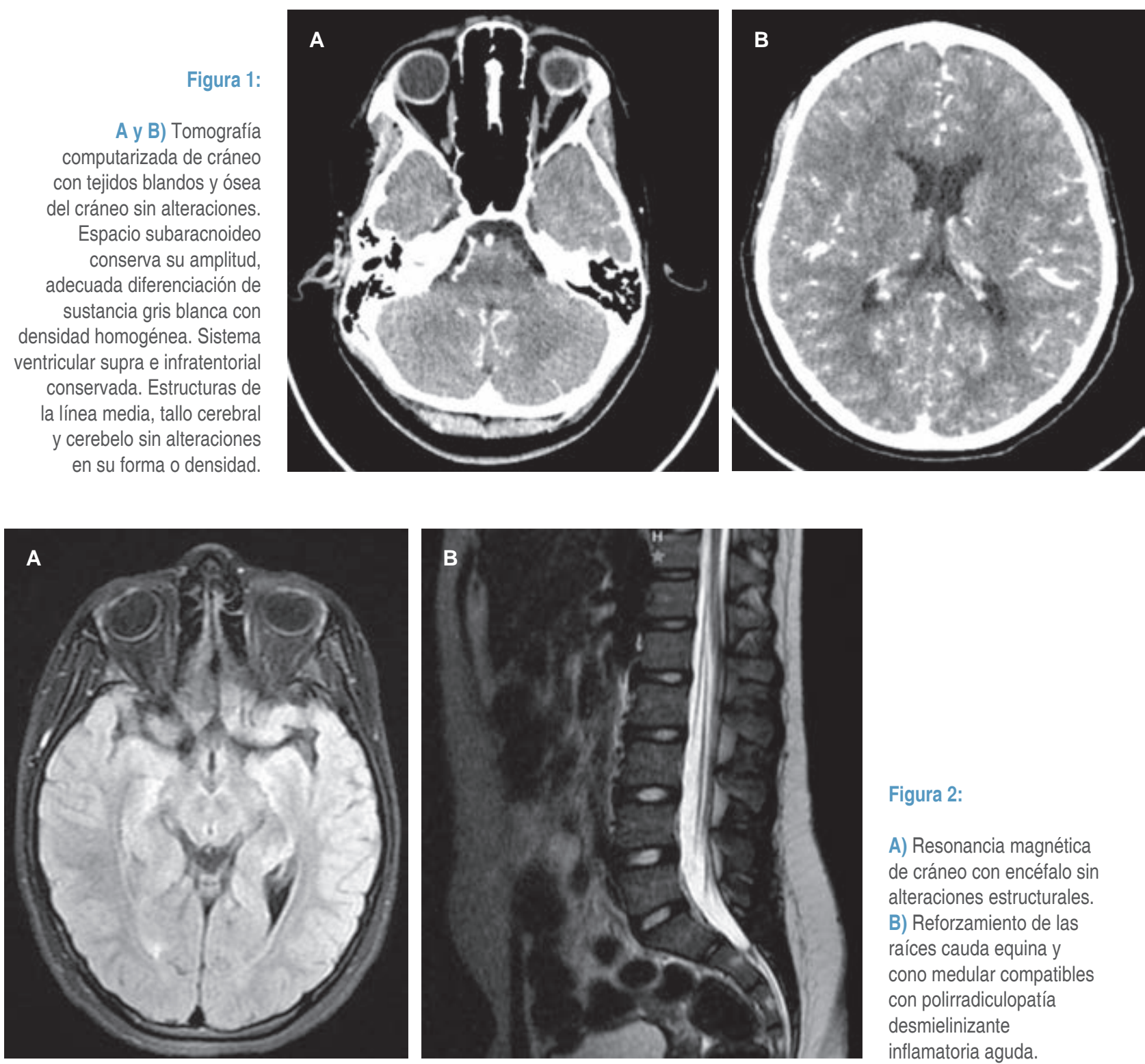

Figura 2:

A) Resonancia magnética
de cráneo con encéfalo sin
alteraciones estructurales.
B) Reforzamiento de las
raíces cauda equina y
cono medular compatibles
con polirradiculopatía
desmielinizante
inflamatoria aguda.

Fue tratada con inmunoglobulina humana inespecífica intravenosa durante cinco días y tres bolos de metilprednisolona. Después del tratamiento, a la exploración física se observó motor con tono conservado. REM en miembros superiores proximal y distal ++/++++, REM en miembros inferiores proximal y distal +/++++. Fuerza muscular en miembros inferiores proximal y distal $5 / 5$, fuerza muscular en miembros superiores $4 / 5$ proximal y $3 / 5$ distal en la escala de Daniels. Egresó del hospital con carbamazepina como tratamiento y continuará su seguimiento en consulta externa.

\section{DISCUSIÓN}

El síndrome de Miller-Fisher tiene una frecuencia del 5 al $10 \%$ de los casos de síndrome de GuillainBarré en adultos, considerándose en niños una enfermedad rara con un curso de menor intensidad, el anticuerpo antigangliósido GQ1b tipo MillerFisher están presentes en el $90 \%$ de los casos. ${ }^{5}$ Los estudios de conducción pueden mostrar alteraciones sutiles o localizadas en tractos específicos, la resonancia magnética puede no evidenciar cambios significativos o precisos que orienten al 
diagnóstico, sin embargo, la alta prevalencia en la elevación del anticuerpo anti-GQ1b se explica por su rol en la fisiopatología de la enfermedad. ${ }^{9,10}$ El coronavirus es ampliamente conocido por sus efectos patológicos en el sistema respiratorio; sin embargo, algunas especies se han asociado a enfermedades desmielinizantes agudas y crónicas (HCoV-229E y HCoV-OC43), siendo este último encontrado con mayor frecuencia en autopsias o estudios dirigidos a pacientes con alguna manifestación neurológica como encefalomielitis diseminada aguda. ${ }^{11,12} \mathrm{De}$ acuerdo con modelos de invasión, el SARS-CoV-2 infecta la neurona periférica, las terminales sinápticas, el cuerpo neuronal y áreas remotas del cerebro, pudiendo desarrollar polineuropatías axonales como parte de un proceso inflamatorio neural a través de mimetismo inmunológico o como parte de un proceso inflamatorio sistémico el cual aún no es claro. ${ }^{13}$

\section{CONCLUSIÓN}

Durante la pandemia por COVID-19 los adultos son los más afectados; por lo tanto, la mayoría de los estudios sobre SARS-CoV-2 se han enfocado en la población adulta. En recientes publicaciones se han descrito manifestaciones clínicas poco frecuentes, pero graves en la población pediátrica, cuya fisiopatología no está bien descrita; por lo cual, es importante aportar información sobre las múltiples implicaciones médicas asociadas con este virus. También es importante continuar con los ensayos clínicos necesarios para que los niños puedan regresar con seguridad a las escuelas y a sus comunidades con una vacuna segura y eficaz contra SARS-CoV-2.

\section{REFERENCIAS}

1. The Novel Coronavirus Pneumonia Emergency Response Epidemiology Team. The Epidemiological Characteristics of an Outbreak of 2019 Novel Coronavirus Diseases (COVID19)-China, 2020. China CDC Weekly. 2020; 2 (8): 113-122.

2. Parcha V, Booker KS, Kalra R, Kuranz S, Berra L, Arora $G$ et al. A retrospective cohort study of 12,306 pediatric COVID-19 patients in the United States. Sci Rep. 2021; 11 (1): 10231. doi: 10.1038/s41598-021-89553-1.
3. Panda PK, Sharawat IK, Panda P, Natarajan V, Bhakat R Dawman L. Neurological complications of SARS-CoV-2 infection in children: a systematic review and meta-analysis. J Trop Pediatr. 2021; 67 (3): fmaa070. doi: 10.1093/tropej/ fmaa070.

4. Abdel-Mannan O, Eyre M, Lobel U, Bamford A, Eltze $C$, Hameed B et al. Neurologic and radiographic findings associated with COVID-19 infection in children. JAMA Neurol. 2020; 77 (11): 1440-1445. doi: 10.1001/ jamaneurol.2020.2687. Erratum in: JAMA Neurol. 2020; 77 (12): 1582.

5. Mane SS, Nagesh U, Sathe VT, Janadhanan J. Miller Fisher variant of Guillain-Barré syndrome in a child. J Pediatr Neurosci. 2020; 15 (1): 60-62. doi: 10.4103/JPN. JPN_146_18.

6. Jang Y, Choi JH, Chae JH, Lim BC, Kim SJ, Jung JH. Pediatric Miller Fisher syndrome; characteristic presentation and comparison with adult Miller Fisher syndrome. J Clin Med. 2020; 9 (12): 3930. doi: 10.3390/jcm9123930.

7. Li Z, Li X, Shen J, Chan MTV, Wu WKK. Miller Fisher syndrome associated with COVID-19: an up-to-date systematic review. Environ Sci Pollut Res Int. 2021; 28 (17): 20939-20944. doi: 10.1007/s11356-021-13233-w.

8. Christy A. COVID-19: a review for the pediatric neurologist. J Child Neurol. 2020; 35 (13): 934-939. doi: 10.1177/0883073820939387.

9. Ajena D, Ferrari S, Romito S, Zaglia F, Biban P, Squintani $G$. A pediatric case of Miller Fisher syndrome with central involvement. Neurol Sci. 2013; 34 (9): 1689-1690. doi: 10.1007/s10072-012-1255-y.

10. Paparounas K. Anti-GQ1b ganglioside antibody in peripheral nervous system disorders: pathophysiologic role and clinical relevance. Arch Neurol. 2004; 61 (7): 1013-1016. doi: 10.1001/archneur.61.7.1013.

11. Principi N, Bosis S, Esposito S. Effects of coronavirus infections in children. Emerg Infect Dis. 2010; 16 (2): 183188. doi: 10.3201/eid1602.090469.

12. Yeh EA, Collins A, Cohen ME, Duffner PK, Faden H. Detection of coronavirus in the central nervous system of a child with acute disseminated encephalomyelitis. Pediatrics. 2004; 113 (1 Pt 1): e73-e76. doi: 10.1542/peds.113.1.e73.

13. Montalvan V, Lee J, Bueso T, De Toledo J, Rivas K. Neurological manifestations of COVID-19 and other coronavirus infections: a systematic review. Clin Neurol Neurosurg. 2020; 194: 105921. doi: 10.1016/j. clineuro.2020.105921.

Financiamiento: Ninguno.

Conflicto de intereses: Ninguno.

Correspondencia:

Dr. Sabino Suárez Hortiales

E-mail: dr.sabinosuarez@gmail.com 